\title{
GRUPUGE Perspective: Endoscopic Ultrasound-Guided Drainage of Peripancreatic Collections
}

\author{
Flávio Pereira $^{a} \quad$ Ana Caldeira $^{a} \quad$ Sílvia Leite $^{b}$ Susana Marques ${ }^{c}$ Teresa Moreirad \\ Pedro Moutinho-Ribeiro ${ }^{e}$ Nuno Nunes ${ }^{f}$ Miguel Bispo $^{c}$ \\ ${ }^{a}$ Department of Gastroenterology, Hospital Amato Lusitano, Castelo Branco, Portugal; ${ }^{b}$ Department of

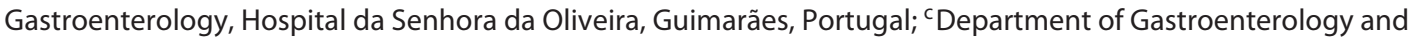 \\ Digestive Endoscopy, Champalimaud Foundation, Lisbon, Portugal; ${ }^{d}$ Department of Gastroenterology, Hospital de \\ Santo António, Porto, Portugal; ' Department of Gastroenterology, Centro Hospitalar e Universitário de São João,

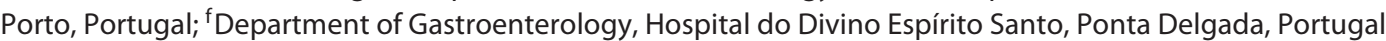

\section{Keywords}

Peripancreatic collections - Endoscopic ultrasoundguided drainage - Endoscopic necrosectomy - Pancreatic pseudocyst $\cdot$ Walled-off pancreatic necrosis

\section{Abstract}

Pancreatic and peripancreatic collections (PPC) are a known complication of acute pancreatitis. They are categorized into four types of collection: (1) acute peripancreatic fluid collection, (2) pseudocyst, (3) acute necrotic collection and (4) walled-off necrosis. Most PPC resolve spontaneously or are persistent but asymptomatic. Intervention is needed in a minority of patients with infected or symptomatic collection. Endoscopic ultrasound-guided transmural drainage is currently the first-line treatment option for PPC management. It has shown great technical and clinical success, similar to percutaneous or surgical approaches, but with lower morbidity and costs and better quality of life. In this review article, the GRUPUGE presents an updated perspective on the potential role of endoscopic ultrasound-guided drainage of peripancreatic collections, addressing the selection criteria and the technical issues of different techniques and analysing emerging data on their efficacy and safety.

(C) 2020 Sociedade Portuguesa de Gastrenterologia Published by S. Karger AG, Basel

karger@karger.com www.karger.com/pjg

Karger

BOPEN ACCESS
(C) 2020 Sociedade Portuguesa de Gastrenterologia Published by S. Karger AG, Basel

This article is licensed under the Creative Commons AttributionNonCommercial-NoDerivatives 4.0 International License (CC BYNC-ND) (http://www.karger.com/Services/OpenAccessLicense) Usage and distribution for commercial purposes as well as any distribution of modified material requires written permission.

\section{Perspectiva do GRUPUGE: drenagem de coleções peripancreáticas guiada por ecoendoscopia}

\section{Palavras Chave}

Coleções peripancreáticas - Drenagem guiada por ecoendoscopia - Necrosectomia endoscópica . Pseudoquisto pancreático · Coleção necrótica encapsulada

\section{Resumo}

As coleções pancreáticas e peripancreáticas constituem uma complicação conhecida de pancreatite aguda. As coleções são classificadas em quatro tipos: (1) coleção líquida peripancreática aguda, (2) pseudoquisto, (3) coleção necrótica aguda e (4) coleção necrótica encapsulada (walled-off necrosis). A maioria das coleções peripancreáticas resolvem espontaneamente ou mantém-se assintomáticas. A drenagem está indicada numa minoria de doentes em que a coleção infecta ou se torna sintomática. A drenagem de coleções peripancreáticas guiada por

Flávio Pereira and Ana Caldeira are co-first authors.

Flávio Pereira

Department of Gastroenterology, Hospital Amato Lusitano Av. Pedro Álvares Cabral PT-6000-085 Castelo Branco (Portugal) pereiraflavio14@gmail.com 
ecoendoscopia é atualmente considerada a primeira linha de tratamento. Os procedimentos guiados por ecoendoscopia têm mostrado uma elevada taxa de sucesso técnico e clínico, semelhante às abordagens cirúrgica e percutânea, mas está associada a menor morbilidade e custos e a melhor qualidade de vida. Neste artigo de revisão, o GRUPUGE apresenta uma perspetiva atualizada do papel da ecoendoscopia na drenagem de coleções peripancreáticas, abordando critérios de seleção e questões técnicas relativas aos diferentes procedimentos, e analisando os dados disponíveis sobre a sua eficácia e segurança.

๑ 2020 Sociedade Portuguesa de Gastrenterologia Publicado por S. Karger AG, Basel

\section{Introduction}

Pancreatic and peripancreatic collections (PPC) are local complications of an acute pancreatic event (acute pancreatitis, pancreatic trauma or pancreatic surgery) or a chronic pancreatic injury (chronic pancreatitis or autoimmune pancreatitis) $[1,2]$. PPC can occur secondary to pancreatic/peripancreatic inflammation or to a disruption of the main pancreatic duct and/or its side branches [1]. PPC are a known local complication of acute pancreatitis and according to the revised Atlanta classification [3] are categorized into four types: (1) acute peripancreatic fluid collection, (2) pseudocyst, (3) acute necrotic collection and (4) walled-off necrosis (WON) (Table 1).

Most acute peripancreatic fluid collections remain sterile and resolve spontaneously without intervention, so that drainage should not be performed because of the risk of infecting an otherwise sterile collection $[3,4]$. Pseudocysts may develop in 5-15\% of patients with acute pancreatitis [5], the majority of which are asymptomatic and present spontaneous regression or resolution (7-60\%) [6]. Pseudocysts may also complicate 20$40 \%$ of cases of chronic pancreatitis, and they are usually asymptomatic as well [7]. For acute necrotic collections, a prospective observational study showed that $43 \%$ presented spontaneous remission and $51 \%$ matured into WON. Furthermore, most WON cases also resolved spontaneously or were persistent but asymptomatic, with only $21 \%$ of patients requiring an intervention [8]. Therefore, intervention is needed for a minority of patients.

In this review article, the Portuguese Group for Ultrasound in Gastroenterology (GRUPUGE) presents a perspective on the potential role of endoscopic ultrasound (EUS)-guided drainage of peripancreatic collections, ad- dressing the selection criteria and technical issues of different techniques and analysing emerging data on their efficacy and safety.

\section{Methods}

A systematic literature search and review was performed until January 2020, using PubMed, MEDLINE, Scopus and Google, using the keywords "acute pancreatitis," "pancreatic pseudocyst," "walled-off pancreatic necrosis," "transmural drainage of pancreatic fluid collections," "endoscopic ultrasound-guided drainage of peripancreatic collections" and "endoscopic necrosectomy." Prospective/comparative studies and international consensus statements/management guidelines were preferred. The final manuscript was revised and approved by all the members of the Governing Board of the GRUPUGE.

\section{Indications for Drainage}

It is currently recommended to perform drainage of a PPC, usually a pseudocyst or a WON, in the following cases:

- Proven or presumed infection of the collection $[1,4,9$, $10]$, which occurs more frequently in necrotic collections and is associated with increased mortality (1239\%) [11]; clinically manifested as new decompensation in a previously stable patient, persisting or increasing elevation of inflammatory parameters (fever, leucocytosis and C-reactive protein), or new or prolonged organ failure or increased need for cardiovascular, respiratory or renal support despite optimal medical therapy in the absence of an alternative source of infection; demonstrated by imaging findings of gas within the collection

- Significant symptoms related to the collection [1, 9-11], such as persistent abdominal pain (often exacerbated by eating), gastric outlet obstruction (nausea and vomiting), obstructive jaundice (due to biliary compression) or pancreatic leakage due to a disrupted duct manifested as pancreatic ascites or pleural effusion

- Abdominal compartment syndrome [9]

The size of the PPC by itself is no longer considered a reason for intervening, as the majority of PPC tend to resolve spontaneously over time [11]. In case of an indication for intervention, in particular for endoscopic drainage, it is important to differentiate a pseudocyst from a WON. As pseudocysts are fluid-only collections, drainage is usually sufficient [6]. However, WON con-
Pereira/Caldeira/Leite/Marques/Moreira/ Moutinho-Ribeiro/Nunes/Bispo 
Table 1. Revised Atlanta classification of pancreatic and peripancreatic fluid collections

\begin{tabular}{|c|c|c|c|c|c|}
\hline & Type of collection & $\begin{array}{l}\text { Time, } \\
\text { weeks }\end{array}$ & Location & Content & Imaging appearance \\
\hline \multirow{2}{*}{$\begin{array}{l}\text { Interstitial } \\
\text { oedematous } \\
\text { pancreatitis }\end{array}$} & $\begin{array}{l}\text { Acute peripancreatic } \\
\text { fluid collection }\end{array}$ & $\leq 4$ & $\begin{array}{l}\text { Extrapancreatic only, usually } \\
\text { in retroperitoneum }\end{array}$ & Fluid only & $\begin{array}{l}\text { Homogeneous, fluid attenuation, no lique- } \\
\text { faction, not encapsulated, may be multiple }\end{array}$ \\
\hline & Pancreatic pseudocyst & $>4$ & $\begin{array}{l}\text { Adjacent or distant to } \\
\text { pancreas }\end{array}$ & Fluid only & $\begin{array}{l}\text { Homogeneous, fluid attenuation, no lique- } \\
\text { faction, encapsulated }\end{array}$ \\
\hline \multirow[t]{2}{*}{$\begin{array}{l}\text { Necrotizing } \\
\text { pancreatitis }\end{array}$} & $\begin{array}{l}\text { Acute necrotic } \\
\text { collection }\end{array}$ & $\leq 4$ & $\begin{array}{l}\text { In parenchyma and/or } \\
\text { extrapancreatic }\end{array}$ & $\begin{array}{l}\text { Fluid and solid } \\
\text { necrotic debris }\end{array}$ & $\begin{array}{l}\text { Heterogeneous, non-liquefied material, } \\
\text { variably loculated, not encapsulated }\end{array}$ \\
\hline & Walled-off necrosis & $>4$ & $\begin{array}{l}\text { In parenchyma and/or } \\
\text { extrapancreatic }\end{array}$ & $\begin{array}{l}\text { Fluid and solid } \\
\text { necrotic debris }\end{array}$ & $\begin{array}{l}\text { Heterogeneous, non-liquefied material, } \\
\text { variably loculated, encapsulated }\end{array}$ \\
\hline
\end{tabular}

tains fluid and solid necrotic debris and may need further debridement of necrotic tissue after initial drainage [6]. For this reason, endoscopic treatment of WON has a lower success rate and higher complication rate and leads to more frequent reinterventions and longer hospital stays compared to drainage of pseudocysts [12]. Magnetic resonance imaging and EUS perform better than computed tomography (CT) for evaluation of the presence and extent of solid necrotic debris within a collection [13].

\section{Role of EUS in PPC Drainage}

Over the last decade, management of PPC has evolved significantly, shifting from primary open surgery towards minimally invasive techniques. In the trials by the Dutch Pancreatitis Study Group [14, 15], EUS-guided drainage and endoscopic necrosectomy were pointed out as less invasive alternatives to surgery for infected necrotizing pancreatitis; no difference in mortality and major morbidity was found between groups, while the rate of pancreatic fistulas and the length of hospital stay were lower in the endoscopy group [14].

Currently, EUS-guided transluminal drainage should be the first-line treatment option $[9,10]$. It is a minimally invasive procedure that involves the creation of a fistulous tract between the PPC and the gastric or duodenal lumen (cystogastrostomy or cystoduodenostomy), followed by placement of a stent to keep the fistula patent and allowing transluminal PPC drainage [6]. It allows management of collections that do not bulge into the gastric lumen and assesses in real time the wall maturity and collection content (fluid only or with the presence of solid necrotic debris), guiding proper treatment strategies. The procedure should be delayed, whenever possible, until at least 4 weeks after initial presentation to allow wall maturation and better necrotic tissue demarcation and liquefaction [9]. As previously mentioned, EUS-guided transluminal drainage is usually sufficient for pseudocysts. However, for WON, endoscopic necrosectomy may be required after drainage.

Other approaches available for PPC management include conventional blind endoscopic transluminal drainage, transpapillary drainage, percutaneous drainage (under ultrasonography or CT guidance) and surgical drainage (laparoscopic necrosectomy via the transperitoneal approach, video-assisted retroperitoneal debridement or open surgical necrosectomy). They can also be combined in complex cases, for example, dual endoscopic and percutaneous drainage, a surgical step-up approach (percutaneous catheter drainage followed by video-assisted retroperitoneal debridement), or endoscopic and surgical drainage [9].

EUS-guided transmural drainage has had similar technical and clinical success to percutaneous or surgical approaches, but with lower morbidity and costs and better quality of life $[6,14,16,17]$. It has also had greater technical success than conventional blind endoscopy $[18,19]$.

Given the several treatment modalities available, patients with PPC should ideally be managed by a multidisciplinary team, considering local expertise, patient comorbidities and type of collection.

\section{Pre-Drainage Evaluation}

Before endoscopic drainage, an evaluation of the patient and the PPC should be performed $[1,6]$ : 

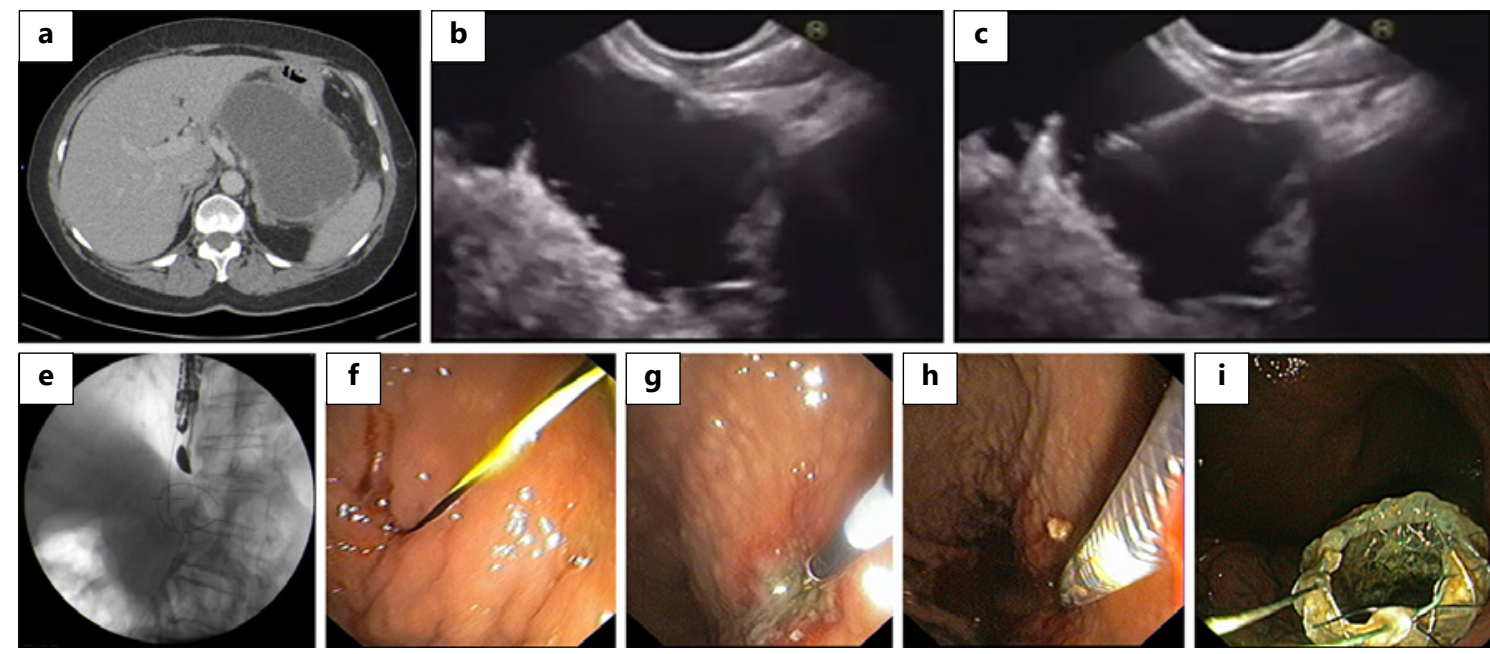

$\mathbf{h}$
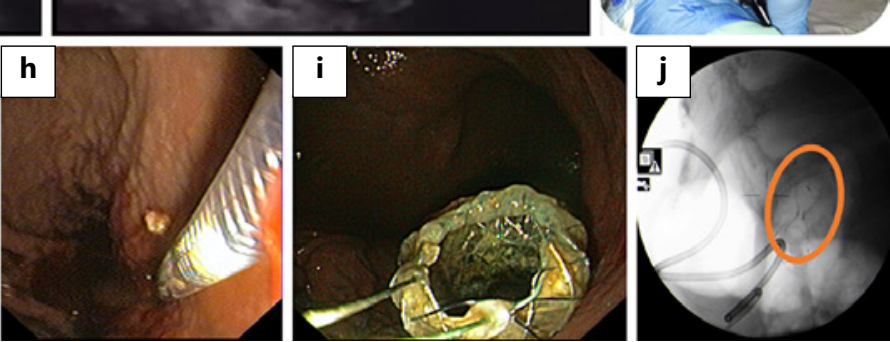

Fig. 1. EUS-guided transmural drainage using a standard approach. a, b Computed tomography (a) and EUS (b) images obtained 6 weeks after a severe pancreatitis episode showing a large homogeneous fluid collection between the pancreatic corpus and the stomach, with a well-defined wall; the findings were consistent with a pseudocyst. c Via a transgastric approach, puncture of the collection using 19-G fine-needle aspiration was performed. d As-

- History and physical examination of the patient, including a documented history of acute or chronic pancreatitis, pancreatic surgery or trauma that may explain the collection

- Laboratory evaluation with coagulation profile and management of antithrombotic/anticoagulant agents as appropriate for high-risk procedure for bleeding

- CT scan assessing the relation between the collection and the stomach or duodenum, giving information about anatomic details (vascular structures, signs of portal hypertension, arterial pseudoaneurysms, ascites, large or atypically located gallbladder, multiple collections) and, although less accurate, possibly also suggesting the presence of solid necrotic debris within the collection

- EUS imaging (possibly at the same session as EUSguided drainage) to localize the collection and its contact zone with the gastric/duodenal lumen, to confirm the development of a mature wall around the collection, to evaluate the presence and extent of solid necrotic debris and to assess for interposed vessels by Doppler mode; furthermore, EUS in combination with fine-needle aspiration and contrast-enhanced ultrasound is helpful in distinguishing a PPC from a cystic neoplasm, avoiding misdiagnosis and guiding proper management decisions piration of purulent fluid from the collection. e, f A 0.035 -inch guidewire is introduced through the needle (e) and is coiled within the pseudocyst under fluoroscopic guidance (f). $\mathbf{g}$ The fistulous tract is dilated using a 10-Fr cystostome. $\mathbf{h}$ Placement of a lumenapposing metal stent (BCF covered Diabolo shape, Hanarostent ${ }^{\circledR}$ ). i Proximal flange of the stent deployed in the stomach. j Stent deployment confirmed by fluoroscopy. EUS, endoscopic ultrasound.

Regarding antibiotic therapy, patients undergoing EUS-guided drainage for infected PPC should continue the previously instituted treatment [1]. The role of prophylactic antibiotics in patients undergoing EUS-guided transmural drainage for non-infectious reasons has not been studied [20]. Nevertheless, patients usually receive periprocedural antibiotics followed by a short course thereafter (often for 3-5 days) [1,20].

EUS-guided drainage should also be performed under deep sedation or anaesthesia given its complexity, and with the availability of surgical, intensive care and interventional radiology support in the event of complications $[10,21]$.

\section{EUS-Guided Transmural Drainage: The Procedure}

\section{Using the Standard Procedure (Fig. 1)}

The standard procedure should be performed in a room with fluoroscopic imaging, as both ultrasonography and fluoroscopy guidance are needed for stent deployment. A therapeutic linear echoendoscope with a working channel of $3.7-3.8 \mathrm{~mm}$ is required in order to enable the insertion of stents or a nasocystic catheter.

1. Begin the procedure with location of the collection and its contact zone with the gastric/duodenal lumen; the 

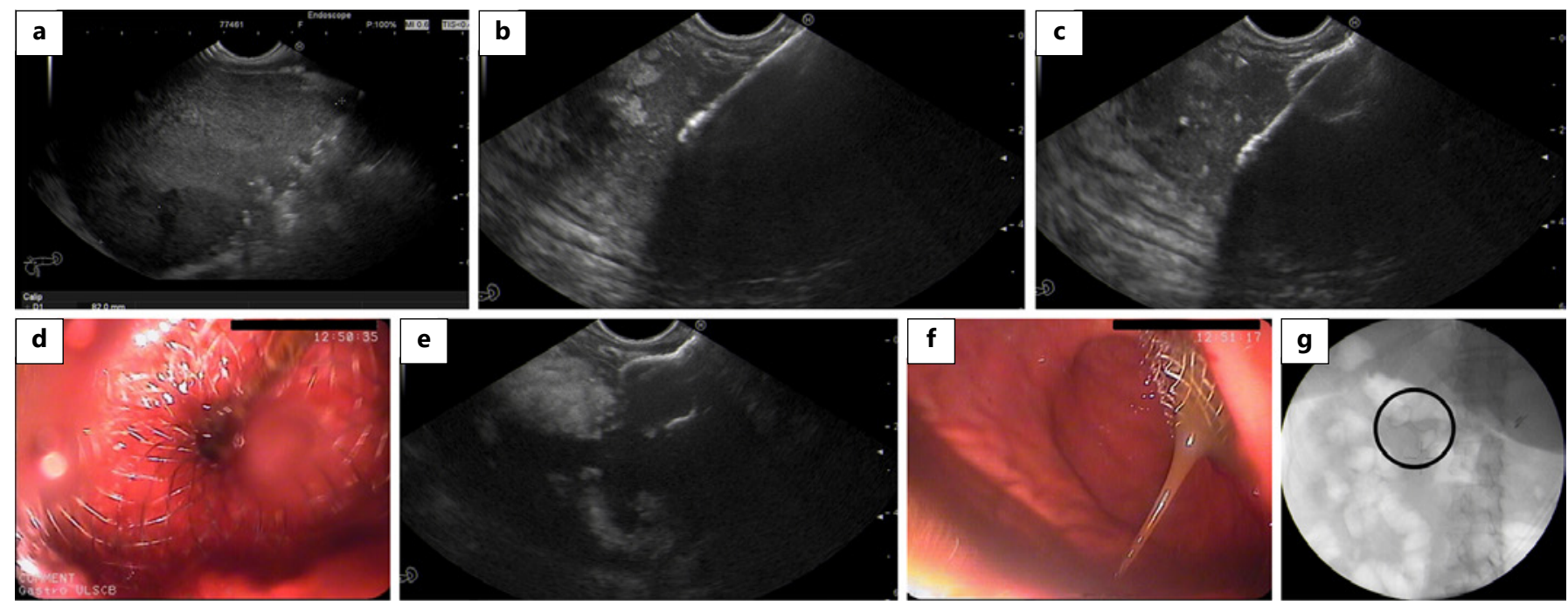

Fig. 2. EUS-guided transmural drainage using a cautery-enhanced lumen-apposing metal stent (Hot AXIOS). a EUS image obtained 4 weeks after severe pancreatitis showing a heterogeneous fluid collection with solid debris and a well-defined wall, localized between the pancreatic corpus and the posterior wall of the stomach; the findings are consistent with walled-off necrosis. b Via the transgastric approach and under EUS guidance, the catheter is ad- vanced into the collection with an electrocautery tip. c The distal flange of the stent is deployed inside the collection. $\mathbf{d}$ The proximal flange of the stent is released and visible in the stomach. e Removal of the delivery system, with the stent deployed across the gastric wall into the collection. $\mathbf{f}$ Proximal flange of the stent deployed in the stomach. g Stent placement confirmed by fluoroscopy. EUS, endoscopic ultrasound. distance between the collection and the gastroduodenal wall should not exceed $10 \mathrm{~mm}$ in order to smooth the procedure and avoid adverse events [22]

2. Assess for interposed vessels by Doppler mode and determine the optimal site for puncture

3. Puncture the collection using $19-\mathrm{G}$ fine-needle aspiration (a sample may be aspirated and sent for laboratory analysis, such as microbiology); a 0.035 -inch guidewire is introduced through the needle and is coiled within the pseudocyst under fluoroscopic guidance

4. Dilate the tract sequentially using endoscopic retrograde cholangiopancreatography cannulas, Soehendra biliary dilators or 6- to 15 -mm over-the-wire biliary balloons; alternatively, a 10-Fr cystostome or a needle knife catheter may be used for dilation

5. For double pigtail plastic stent (PS) placement, introduce an additional guidewire through the fistulous tract and place the two PS, usually of a calibre of 7 $10 \mathrm{Fr}$

6. For fully covered self-expandable metallic stent or lumen-apposing metal stent (LAMS) placement, introduce the stent delivery device through the tract over the wire and deploy the stent

\section{Using a Cautery-Enhanced LAMS (Fig. 2)}

The delivery system comes with an electrocautery wire at the distal tip of the catheter designed for simultaneous puncture and tract dilation followed by stent deployment, without the need for guidewire placement. After choosing the optimal site for puncture, the electrocautery tip allows passage of the deployment device into the PPC followed by stent placement. With this delivery system, the procedure is performed under EUS and/or endoscopic guidance, whereas fluoroscopic control is not needed.

\section{Stents in Transmural Drainage}

Currently available stents include PS, fully covered self-expanding metal stents (FCSEMS) and LAMS.

\section{Using PS (Fig. 3)}

Traditionally, PS were used for transmural drainage [6]. The type of PS used may be straight or pigtail. Double pigtail PS are more frequently chosen, since they are less prone to migrate into or out of the collection [1]. Moreover, straight stents can cause delayed bleeding from friction of the stent against the wall of the cavity or stomach as the collection resolves [1]. 
Fig. 3. Plastic and fully covered self-expanding metal stents. a Straight plastic stents. b Double pigtail plastic stent. c VIABIL biliary metal stents $\left(\right.$ GORE $\left.^{\circledR}\right)$. d WallFlex biliary metal stent (Boston Scientific ${ }^{\circledR}$ ).

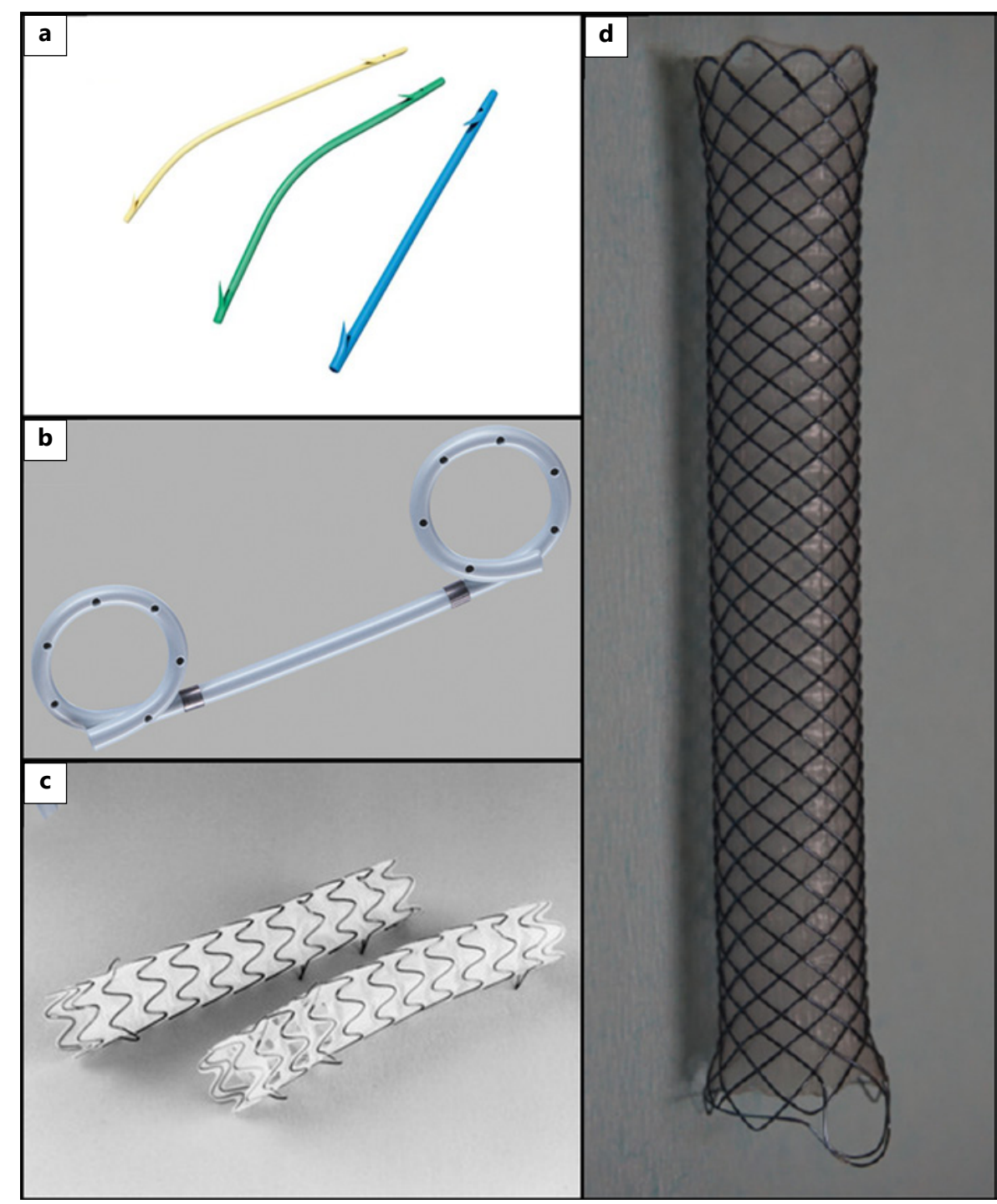

For pancreatic pseudocysts, transmural stenting using double pigtail PS showed high efficacy (85.1-90.8\%) [2325]. Nevertheless, treatment success is significantly lower for drainage of WON (69.5-81.8\%) [23-25], which may be explained by the small diameter of PS and the presence of solid debris in WON that causes stent occlusion and hampers drainage through the fistulous tract [11]. Therefore, the main disadvantage of PS is their small bore with need to access the collection cavity several times or to use various guidewires to place multiple stents in order to maintain drainage, which is labourintensive and time-consuming [26]. Furthermore, a 10Fr PS can be hard to advance and deploy through the 3.7- to 3.8- $\mathrm{mm}$ channel of the echoendoscope [26], so narrower stents are frequently used ( 7 or $8.5 \mathrm{Fr})$. Repeat balloon dilation of the fistulous tract is also needed to permit endoscopic necrosectomy.

\section{Using FCSEMS (Fig. 3)}

Straight biliary or oesophageal FCSEMS have been tried in patients with PPC due to theoretical advantages over PS. Given their larger stent diameter, they can facilitate drainage of both liquid and the viscous necrotic debris, decreasing the risk of stent occlusion and the need for repeat procedures $[2,25]$. They also may shorten the duration of the procedure, since they require a single access to the collection for stent delivery, rather than multiple access points as required for the deployment of multiple PS [2]. Due to its tubular configuration lacking anchoring flanges, the main disadvantage of FCSEMS is stent migra- 
Fig. 4. Lumen-apposing metal stents. a NAGI stent (TaeWoong Medical). b SPAXUS stent (TaeWoong Medical). c BCF covered Diabolo shape stent (Hanarostent ${ }^{\circledR}$ ). d Hot AXIOS stent (Boston Scientific).

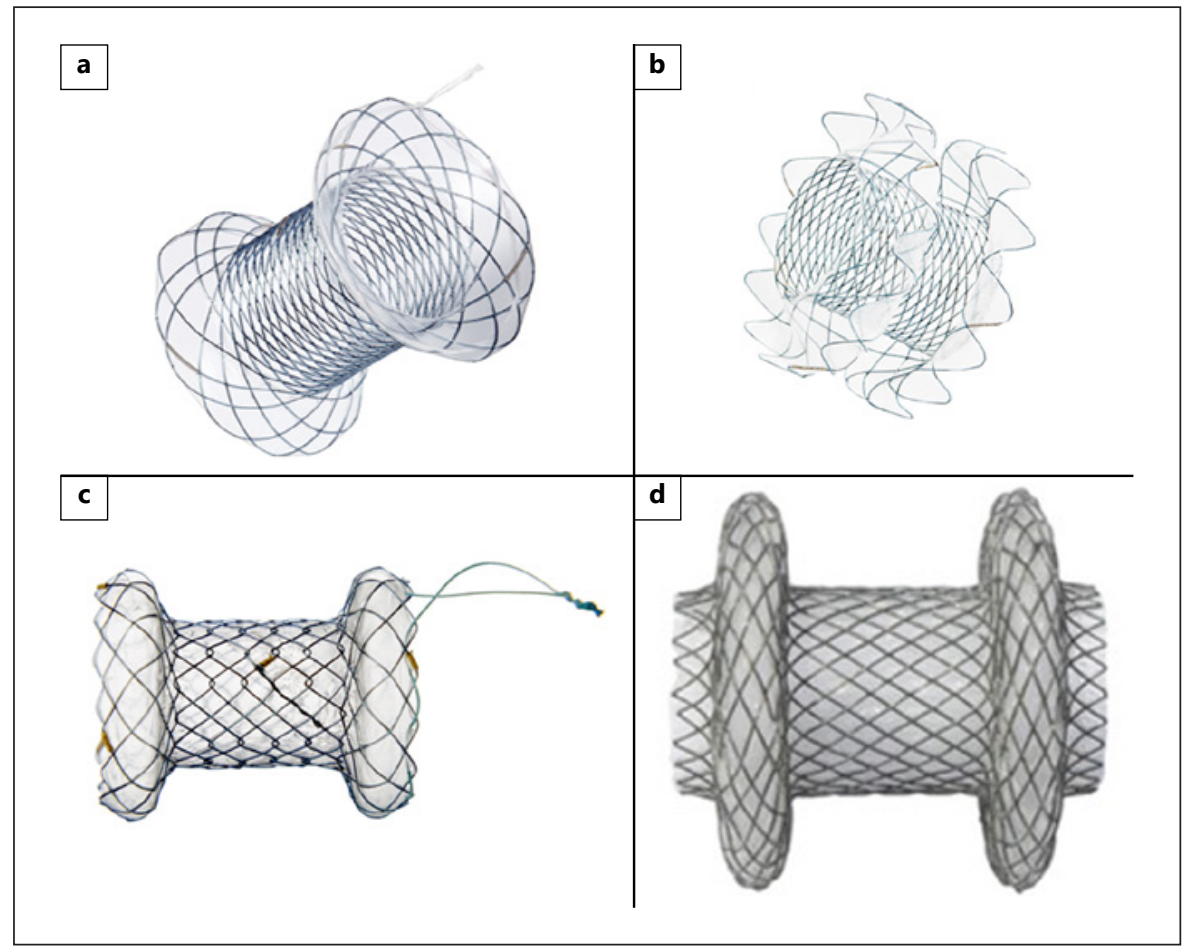

tion [26], so that a single double pigtail PS is usually placed within the FCSEMS in order to maintain stent patency as the cavity resolves as well as to prevent migration [1].

A few studies reported great treatment success with EUS-guided drainage of pseudocysts using FCSEMS (78$100 \%$ ) [2]. In a retrospective cohort study evaluating EUS-guided drainage of pancreatic pseudocysts [27], FCSEMS achieved higher complete resolution rates $(98$ vs. $89 \% ; p=0.01$ ) and fewer early adverse events (14 vs. $31 \%, p=0.008)$ than PS.

\section{Using LAMS (Fig. 4)}

LAMS have been increasingly used in PPC management, especially for WON, because the larger diameter of the stent facilitates drainage and can accommodate the repeated endoscope entry and exit necessary for necrosectomy [1]. LAMS also have a "dumb-bell" configuration with two wide flanges that provides stable apposition between the digestive wall and the collection wall, avoiding stent migration [1].

Some authors suggest placing a single double pigtail PS within the LAMS in order to allow egress of fluid in the event that necrotic material impacts the LAMS lumen, to protect the inner wall of the collection and prevent contact-related delayed bleeding, allow retrieval of buried LAMS (if it occurs) and create space if long-term double

EUS-Guided Drainage of Peripancreatic Collections pigtail stents are needed to manage disconnected pancreatic duct syndrome [1].

In a meta-analysis [28], LAMS had high technical and clinical success in the management of both pancreatic pseudocysts (86-99\% and 93-99\%, respectively) and WON (82-100\% and 64-98\%, respectively) [28].

\section{Plastic versus Metal Stents}

In an RCT comparing EUS-guided drainage for symptomatic WON using LAMS or double pigtail PS $[29,30]$, there was no significant difference in total number of procedures performed, treatment success, readmissions and length of hospital stay. The procedure duration was shorter with LAMS (15 vs. $40 \mathrm{~min} ; p<0.001$ ), and although the procedure costs were higher with LAMS, overall treatment costs were similar between groups. An interim audit was performed due to a higher-than-anticipated procedural adverse event rate in the LAMS cohort (50 vs. $0 \% ; p=0.019$ ) observed 3 or more weeks after LAMS placement. The authors hypothesized that the wide diameter of the LAMS facilitated better drainage of the necrotic contents, leading to faster WON resolution. Due to its immobility, the LAMS remained in place, causing friction with the adjacent vasculature surrounding the necrotic cavity, thereby precipitating bleeding, occlusion and buried stent syndrome. Therefore, an amendment 
was made to the study protocol, including a CT scan 3 weeks after LAMS placement, followed by stent removal if WON had resolved. After protocol amendment, there was no significant difference in adverse events between cohorts.

A prospective case control study [31] was also conducted to compare biliary FCSEMS and LAMS in patients with PPC drained under EUS guidance. The use of a double pigtail PS to prevent metal stent migration, as well as the use of a nasocystic catheter for cavity lavage, was significantly less frequent with LAMS than with FCSEMS (33 vs. $100 \%$ and 13 vs. $58 \%$, respectively; $p<0.0001$ ). All procedures for LAMS placement took less than $30 \mathrm{~min}$, while all FCSEMS placements took over $30 \mathrm{~min}$ ( $p=$ $0.0001)$. The LAMS cohort also had greater clinical success, but not statistically significantly so ( 96 vs. $82 \%, p=$ 0.055 ), as well as a lower adverse event rate (4 vs. $18 \%$; $p=0.04)$.

In a systematic review including 5 retrospective cohort studies comparing PS and LAMS [32], overall WON resolution was more likely to occur with LAMS than with PS (91.5 vs. $80.9 \%$; OR $=2.5$; 95\% CI: $1.4-4.3 ; p=0.001$ ). Furthermore, 2 systematic reviews, including comparative studies between plastic and metal stents (FCSEMS and/or LAMS) [23, 25], also demonstrated a higher rate of clinical success and a lower rate of adverse events with metal stents for both pseudocysts and WON. In contrast, 2 other systematic reviews $[24,33]$ showed no difference in overall treatment success or rates of adverse events between PS and metal stents.

Based on current evidence, the European Society of Gastrointestinal Endoscopy (ESGE) suggests either PS or LAMS for initial endoscopic transmural drainage [9]. Pseudocysts will most likely resolve with transmural placement of two double pigtail PS or one metal stent (FCSEMS or LAMS). For management of WON, some experts suggest the use of metal stents (preferentially LAMS) as first-line treatment given the apparent higher efficacy in drainage and the likelihood of endoscopic necrosectomy. However, more data are needed from welldesigned prospective trials in order to clarify the effective superiority of metal stents (and LAMS in particular).

\section{Stent Removal after Drainage}

The PPC recurrence rate in the first year after stent removal is reported to be around 10-38\% [11]. Prolonged transluminal stenting with PS may maintain the patency of the fistulous tract and prevent recurrence. However, retrieval of LAMS is recommended within 4 weeks after placement to prevent stent-related adverse effects [9].
Prior to stent removal, imaging of the main pancreatic duct by CT, magnetic resonance cholangiopancreatography (preferably with secretin) or endoscopic retrograde cholangiopancreatography is suggested in order to rule out disruption and disconnected pancreatic duct syndrome $[9$, 13]. Disruption of the pancreatic duct may occur in 40 $60 \%$ of patients with PPC and leaves a functioning body or tail disconnected from the head of the pancreas, with ongoing leakage of pancreatic exocrine secretions leading to persistence or recurrence of the PPC [11]. Patients with partial rupture of the pancreatic duct benefit from placement of a transpapillary pancreatic stent to bridge the site of the leak and facilitate preferential drainage via the main pancreatic duct (since transmural drainage does not directly treat the pancreatic duct disruption) [34]. When the disruption is complete or stent bridging of a partial rupture fails, long-term indwelling of transmural PS is recommended after PPC drainage [9]. In case a metal stent (FCSEMS or LAMS) was placed for transmural PPC drainage, this should be replaced by a PS [9].

\section{Endoscopic Management of Necrotic Debris}

As previously mentioned, treatment success for WON is significantly lower than for pseudocysts [12], because clearing of solid necrotic debris may be incomplete with only drainage, and further management is needed.

Several approaches have been proposed for endoscopic management of necrotic debris: (1) irrigation, (2) the multiple transluminal gateway technique, (3) endoscopic necrosectomy and (4) the dual-modality drainage technique.

\section{Irrigation Technique}

In order to facilitate debridement of necrotic tissue, a nasocystic catheter (5-7 Fr) may be inserted during the access procedure to the PPC, alongside the PS or within the deployed metal stent [9]. Through the nasocystic tube, continuous or sequential irrigation of the PPC with normal saline solution is applied during the first $48-72 \mathrm{~h}$ or between each necrosectomy session (for a daily volume of $500-1,500 \mathrm{~mL}$ ). In a retrospective study using double pigtail PS [35], the placement of a nasocystic tube led to a significantly greater treatment success at the 1 -month follow-up ( 85 vs. $63 \% ; p=0.03$ ), but no significant differences at 12 months (79 vs. $58 \% ; p=0.059$ ), compared to PS alone. A retrospective study using LAMS [36] also showed no statistically significant difference in the overall success of WON resolution with and without nasocystic
GE Port J Gastroenterol 2021;28:39-51 DOI: $10.1159 / 000509193$
Pereira/Caldeira/Leite/Marques/Moreira/ Moutinho-Ribeiro/Nunes/Bispo 

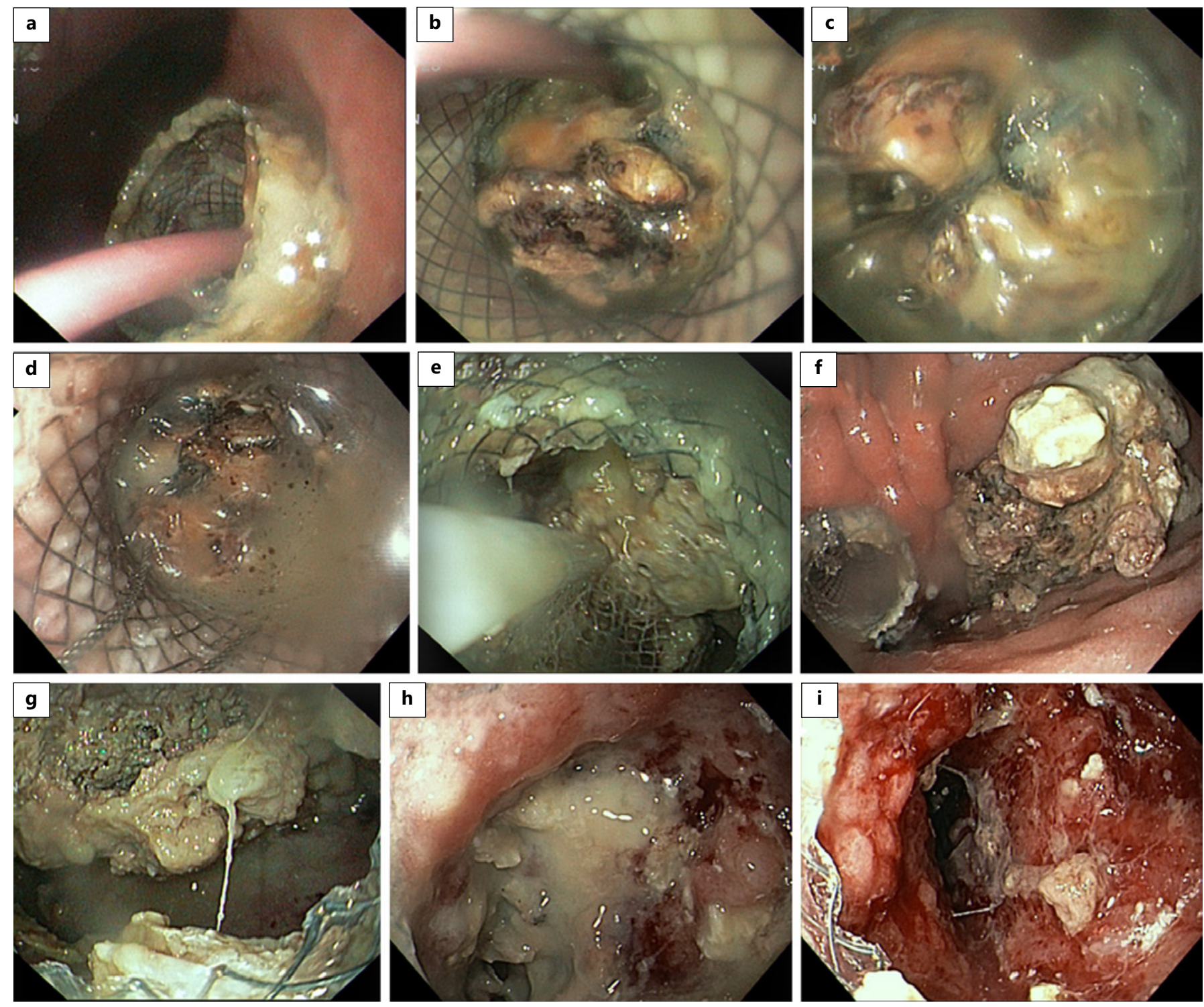

Fig. 5. Direct endoscopic necrosectomy. A nasocystic catheter, placed through the stent (lumen-apposing metal stent) inside the cavity, is removed (a, b). Using forceps (c), a polypectomy snare (d) and a net (e), necrotic debris is removed to the stomach (f).
Progressive resolution of the walled-off necrosis is seen with necrosectomy $(\mathbf{g}, \mathbf{h})$, showing pink granulation tissue on the cavity wall (i). tube placement at the 3-month follow-up (90.9 vs 95.6\%; $p=0.59)$. In 1 study, antibiotics were also added to the irrigation solution according to the microbiological findings [37]. Therefore, it is unclear if this technique has any advantage, especially when combined with a metal stent (LAMS in particular).

Another irrigation technique is to perform lavage of the collection cavity through the working channel of the endoscope during the necrosectomy session [9]. In 1 noncomparative study including 12 patients with WON [38], lavage sessions were performed by flushing normal saline solution (500-1,500 mL) through the LAMS using a water jet system, followed by total aspiration of the flushed solution and removal of all non-adherent necrotic material. The authors reported a clinical success in all patients, without the need for direct mechanical necrosectomy [38]. Some studies also employed lavage with an antibacterial solution $[39,40]$ or hydrogen peroxide-saline solution [30] in order to remove bacterial biofilm and assist with debridement. 


\section{Multiple Transluminal Gateway Technique}

This modality consists of the creation of 2-3 fistulous tracts (rather than a single one) between the WON and the gastric or duodenal lumen in order to facilitate better drainage of necrotic material and fluid [41]. One tract may serve for irrigation through a nasocystic tube and the others for drainage through deployed stents $[6,41]$. The multiple transluminal gateway technique can be considered for patients with multiple or large $(>12-\mathrm{cm}) \mathrm{WON}$, with a suboptimal response to single transluminal gateway drainage, or when the position of first access hampers the introduction of the endoscope into the cavity for necrosectomy [9]. Two retrospective studies [42, 43] showed greater treatment success with the multiple transluminal gateway technique than with single drainage using PS. A case of successful use of LAMS in multiple transluminal drainage has also been published [44].

\section{Endoscopic Necrosectomy}

Another technique for the management of necrotic tissue consists of its mechanical removal from the collection cavity; it is named endoscopic necrosectomy. It can be performed by removal of necrotic debris using accessories or devices introduced from the digestive lumen into the collection (transluminal endoscopic necrosectomy) or by insertion of the endoscope into the cavity to remove the necrotic debris (direct endoscopic necrosectomy) [9] (Fig. 5).

The location of drainage is important if necrosectomy is foreseen, because a too proximal (fundus, cardia) or a too distal (antrum) access may compromise the direct introduction of the endoscope into the cavity and render its manipulation more difficult [9].

Concerning stent choice, as previously mentioned, LAMS carry some theoretical advantages over other stents: (1) a larger diameter enabling passage of an endoscope through the stent for direct endoscopic necrosectomy, (2) avoidance of multiple stents or repeated balloon dilations and (3) wider flanges that provide stable apposition $[1,11]$. However, prospective studies are needed to confirm the effective superiority of LAMS.

There is no consensus regarding the optimal timing for direct endoscopic necrosectomy. It is typically delayed a few days after stent placement, in order to allow maturation of the fistulous tract and decrease the risk of dislodgement, and also because some WON can resolve with stent drainage alone [45]. Nevertheless, a retrospective multicentre study [46] compared immediate (same session as stent placement) and delayed (1 week after stent placement) direct necrosectomy using LAMS and showed no significant difference in clinical success rates between the two groups. Overall adverse events were similar, though stent dislodgements were more frequent in the immediate-necrosectomy group ( 4.3 vs. $0 \%$; $p=0.016$ ) and all occurred at the index endoscopy during necrosectomy; the stent was successfully repositioned with grasping forceps in all patients without complications.

Data comparing the types of endoscope used for endoscopic necrosectomy are lacking. The ESGE suggests the use of a therapeutic gastroscope due to its larger working channel that may facilitate evacuation of fluids and entry of equipment to be used for necrosectomy [9].

No specifically designed accessories or devices are available for necrosectomy. It is performed by a combination of irrigation, sucking debris through the working channel and removing necrotic material with a removal device (such as polypectomy snares, nets, tripod retrieval forceps, grasping/rat-tooth/pelican forceps, Dormia or other stone removal baskets, or EndoRotor devices) [9, 47]. There are no studies comparing the efficacy or safety of these accessories. Snares and baskets might be preferred for the primary attempt as they are safe and quite effective [9]. The EndoRotor (Interscope Medical, Whitinsville, MA, USA), a novel automated non-thermal mechanical system designed for polyp resection in the gastrointestinal tract, is also being studied in the setting of necrosectomy and allows the necrotic tissue to be sucked into a catheter using negative pressure, cut by a rotating blade and removed to a vacuum container [47]. The ESGE suggests restraint regarding the use of high-flow water jet systems, hydrogen peroxide or vacuum-assisted closure systems [9].

Concerning insufflation during transmural drainage and/or necrosectomy, the utilization of carbon dioxide instead of room air is recommended in order to reduce the risk of air embolism $[9,48]$. Suspected or likely air embolism was reported in $0.9-2 \%$ of the procedures when air insufflation was used during necrosectomy [9]. Carbon dioxide is rapidly absorbed and highly soluble in water or blood, and no cases of air embolism have been documented with carbon dioxide insufflation [9]. Nevertheless, gas insufflation should be minimized during necrosectomy to maintain minimal gas pressure within the retroperitoneum [9].

Again, no criteria for WON resolution have been defined, but some have been proposed: more than $40 \%$ necrotic tissue disappearance within 1 month; the combination of clinical response with complete resolution of fluid collection on CT scans; the combination of granulation pink tissue in almost all walls of the cavity with significant cavity reduction on CT scans; or the combination of clinical response with pink granulation tissue on the cavity wall [41].
Pereira/Caldeira/Leite/Marques/Moreira/ Moutinho-Ribeiro/Nunes/Bispo 
Regarding stent removal, as previously mentioned, it has been suggested that an assessment should be made for disruption of the main pancreatic duct before transluminal drainage is removed [9]. In case an LAMS has been used, retrieval within 4 weeks after placement is recommended [9].

\section{Dual-Modality Drainage Technique}

Combined transluminal and percutaneous drainage can be advantageous in the setting of WON extending to the paracolic gutters, given its difficult resolution with only endoscopic transmural techniques [1]. Compared to percutaneous drainage alone, the combined approach led to a shorter length of hospitalization and duration of external drainage and a lower number of drains [49]. Dualmodality drainage was also associated with a low incidence of external pancreatic fistulas [49].

\section{Complications}

Adverse events associated with EUS-guided transmural drainage can occur early during the stent deployment phase or late due to subsequent effects of the intervention. They may include bleeding (up to 18\%), free perforation (up to $4 \%$ ), stent maldeployment, migration, occlusion, secondary infection, aspiration of gastric content, air embolism, abdominal pain, post-procedure fever, gastric outlet obstruction, pancreatic duct damage and sedationrelated complications $[1,24,48]$.

Adverse events may also arise during endoscopic necrosectomy. Based on a systematic review [50], complications occurred in $36 \%$ of the patients. The most common complication was bleeding (18\%). Pancreatic fistula occurred in $5 \%$, spontaneous perforation of a hollow organ (excluding the stomach/duodenum, due to the intervention) in $4 \%$, and air embolism in $1 \%$ of the patients.

Early recognition and management are essential to avoid long-term sequelae and poor outcomes. Therefore, endoscopic drainage and necrosectomy of PPC should be performed with the availability of surgical and interventional radiology support [1].

\section{Key Points}

- PPC are a known complication of acute pancreatitis. They can also occur secondary to pancreatic trauma or surgery, chronic pancreatitis or autoimmune pancreatitis.

- PPC are categorized into four types: (1) acute peripancreatic fluid collection, (2) pancreatic pseudocyst, (3) acute necrotic collection and (4) WON.

- Most PPC either resolve spontaneously or are persistent but asymptomatic. Intervention is needed for a minority of patients with infected or symptomatic PPC.

- EUS-guided transmural drainage is the technique of choice for PPC management.

- The procedure should be delayed, whenever possible, until at least 4 weeks after initial presentation to allow wall maturation and better necrotic tissue demarcation and liquefaction.

- Differentiation between a pseudocyst and WON is important, since the former will likely need only drainage, while the latter may need further debridement of necrotic tissue after initial drainage.

- Both metal stents and PS lead to great treatment success, although metal stents may offer some advantages.

\section{Conflict of Interest Statement}

The authors have no conflicts of interest to declare.

\section{Funding Sources}

There were no funding sources.

\section{Author Contributions}

Flávio Pereira and Ana Caldeira contributed to the concept and design of the article, literature review, and draft of the manuscript. All authors critically reviewed and approved the final version to be published.
References

EUS-Guided Drainage of Peripancreatic Collections
1 Law R, Baron TH. 56 - Endoscopic Drainage of Pancreatic Pseudocysts, Abscesses, and Walled-Off (Organized) Necrosis [Internet]. Ercp (Third Edition). Elsevier; 2019. pp. 525537.e2. Available from: https://doi.org/ 10.1016/B978-0-323-48109-0.00056-0.
2 Tyberg A, Karia K, Gabr M, Desai A, Doshi R, Gaidhane M, et al. Management of pancreatic fluid collections: a comprehensive review of the literature. World J Gastroenterol. 2016 Feb;22(7):2256-70. 
3 Banks PA, Bollen TL, Dervenis C, Gooszen HG, Johnson CD, Sarr MG, et al.; Acute Pancreatitis Classification Working Group. Classification of acute pancreatitis - 2012: revision of the Atlanta classification and definitions by international consensus. Gut. 2013 Jan;62(1):102-11.

4 Foster BR, Jensen KK, Bakis G, Shaaban AM, Coakley FV. Revised Atlanta classification for acute pancreatitis: a pictorial essay. Radiographics. 2016 May-Jun;36(3):675-87.

5 Poornachandra KS, Bhasin DK, Nagi B, Sinha SK, Rana SS, Shafiq N, et al. Clinical, biochemical, and radiologic parameters at admission predicting formation of a pseudocyst in acute pancreatitis. J Clin Gastroenterol. $2011 \mathrm{Feb} ; 45(2): 159-63$.

6 Giovannini M. Endoscopic UltrasoundGuided Drainage of Pancreatic Fluid Collections. Gastrointest Endosc Clin N Am. 2018 Apr;28(2):157-69.

7 Song TJ, Lee SS. Endoscopic drainage of pseudocysts. Clin Endosc. 2014 May;47(3):222-6.

8 Sarathi Patra P, Das K, Bhattacharyya A, Ray S, Hembram J, Sanyal S, et al. Natural resolution or intervention for fluid collections in acute severe pancreatitis. Br J Surg. 2014 Dec; 101(13):1721-8.

9 Arvanitakis M, Dumonceau JM, Albert J, Badaoui A, Bali MA, Barthet M, et al. Endoscopic management of acute necrotizing pancreatitis: european Society of Gastrointestinal Endoscopy (ESGE) evidence-based multidisciplinary guidelines. Endoscopy. 2018 May; 50(5):524-46.

10 Fusaroli P, Jenssen C, Hocke M, Burmester E, Buscarini E, Havre RF, et al. EFSUMB Guidelines on Interventional Ultrasound (INVUS), Part V - EUS-Guided Therapeutic Interventions (short version). Ultraschall Med. 2016 Aug;37(4):412-20.

11 Alali A, Mosko J, May G, Teshima C. Endoscopic ultrasound-guided management of pancreatic fluid collections: update and review of the literature. Clin Endosc. 2017 Mar; 50(2):117-25.

12 Varadarajulu S, Bang JY, Phadnis MA, Christein JD, Wilcox CM. Endoscopic transmural drainage of peripancreatic fluid collections: outcomes and predictors of treatment success in 211 consecutive patients. J Gastrointest Surg. 2011 Nov; 15(11):2080-8.

13 Dhaka N, Samanta J, Kochhar S, Kalra N, Appasani S, Manrai M, et al. Pancreatic fluid collections: what is the ideal imaging technique? World J Gastroenterol. 2015 Dec;21(48): 13403-10.

14 van Brunschot S, van Grinsven J, van Santvoort $\mathrm{HC}$, Bakker OJ, Besselink MG, Boermeester MA, et al.; Dutch Pancreatitis Study Group. Endoscopic or surgical step-up approach for infected necrotising pancreatitis: a multicentre randomised trial. Lancet. 2018 Jan;391(10115):51-8.
15 Bakker OJ, van Santvoort HC, van Brunschot S, Geskus RB, Besselink MG, Bollen TL, et al.; Dutch Pancreatitis Study Group. Endoscopic transgastric vs surgical necrosectomy for infected necrotizing pancreatitis: a randomized trial. JAMA. 2012 Mar;307(10):1053-61.

16 Seifert H, Biermer M, Schmitt W, Jürgensen C, Will U, Gerlach R, et al. Transluminal endoscopic necrosectomy after acute pancreatitis: a multicentre study with long-term follow-up (the GEPARD Study). Gut. 2009 Sep; 58(9):1260-6.

17 Varadarajulu S, Bang JY, Sutton BS, Trevino JM, Christein JD, Wilcox CM. Equal efficacy of endoscopic and surgical cystogastrostomy for pancreatic pseudocyst drainage in a randomized trial. Gastroenterology. 2013 Sep; 145(3):583-90.e1.

18 Varadarajulu S, Christein JD, Tamhane A, Drelichman ER, Wilcox CM. Prospective randomized trial comparing EUS and EGD for transmural drainage of pancreatic pseudocysts (with videos). Gastrointest Endosc. 2008 Dec;68(6):1102-11.

19 Park DH, Lee SS, Moon SH, Choi SY, Jung SW, Seo DW, et al. Endoscopic ultrasound-guided versus conventional transmural drainage for pancreatic pseudocysts: a prospective randomized trial. Endoscopy. 2009 Oct;41(10):842-8.

20 Khashab MA, Chithadi KV, Acosta RD, Bruining DH, Chandrasekhara V, Eloubeidi MA, et al.; ASGE Standards of Practice Committee. Antibiotic prophylaxis for GI endoscopy. Gastrointest Endosc. 2015 Jan;81(1):81-9.

21 Muthusamy VR, Chandrasekhara V, Acosta RD, Bruining DH, Chathadi KV, Eloubeidi MA, et al.; ASGE Standards of Practice Committee. The role of endoscopy in the diagnosis and treatment of inflammatory pancreatic fluid collections. Gastrointest Endosc. 2016 Mar;83(3):481-8.

22 Rana SS, Shah J, Kang M, Gupta R. Complications of endoscopic ultrasound-guided transmural drainage of pancreatic fluid collections and their management. Ann Gastroenterol. 2019 Sep-Oct; 32(5):441-50.

23 Yoon SB, Lee IS, Choi MG. Metal versus plastic stents for drainage of pancreatic fluid collection: a meta-analysis. United European Gastroenterol J. 2018 Jun;6(5):729-38.

24 Bang JY, Hawes R, Bartolucci A, Varadarajulu S. Efficacy of metal and plastic stents for transmural drainage of pancreatic fluid collections: a systematic review. Dig Endosc. 2015 May;27(4):486-98.

25 Saunders R, Ramesh J, Cicconi S, Evans J, Yip VS, Raraty M, et al. A systematic review and meta-analysis of metal versus plastic stents for drainage of pancreatic fluid collections: metal stents are advantageous. Surg Endosc. 2019 May;33(5):1412-25.

26 Penn DE, Draganov PV, Wagh MS, Forsmark CE, Gupte AR, Chauhan SS. Prospective evaluation of the use of fully covered self-expanding metal stents for EUS-guided transmural drainage of pancreatic pseudocysts. Gastrointest Endosc. 2012 Sep;76(3):679-84.
27 Sharaiha RZ, DeFilippis EM, Kedia P, Gaidhane M, Boumitri C, Lim HW, et al. Metal versus plastic for pancreatic pseudocyst drainage: clinical outcomes and success. Gastrointest Endosc. 2015 Nov;82(5):822-7.

28 Han D, Inamdar S, Lee CW, Miller LS, Trindade AJ, Sejpal DV. Lumen Apposing Metal Stents (LAMSs) for Drainage of Pancreatic and Gallbladder Collections: A Meta-Analysis. J Clin Gastroenterol. 2018 Oct;52(9):83544.

29 Bang JY, Hasan M, Navaneethan U, Hawes R, Varadarajulu S. Lumen-apposing metal stents (LAMS) for pancreatic fluid collection (PFC) drainage: may not be business as usual. Gut. 2017 Dec;66(12):2054-6.

30 Bang JY, Navaneethan U, Hasan MK, Sutton B, Hawes R, Varadarajulu S. Non-superiority of lumen-apposing metal stents over plastic stents for drainage of walled-off necrosis in a randomised trial. Gut. 2019 Jul;68(7):1200-9.

31 Garcia Garcia de Paredes A, Gonzalez Martin JA, Foruny Olcina JR, Juzgado Lucas D, Gonzalez Panizo F, Lopez Duran S, et al. Lumenapposing metal stents versus biliary fully-covered metal stents for EUS-guided drainage of pancreatic fluid collections: a case control study. Meeting presentations: European Society of Gastrointestinal Endoscopy ESGE Days 2018. Endosc Int Open. 2020;8(1):E6-E12.

32 Bazerbachi F, Sawas T, Vargas EJ, Prokop LJ, Chari ST, Gleeson FC, et al. Metal stents versus plastic stents for the management of pancreatic walled-off necrosis: a systematic review and meta-analysis. Gastrointest Endosc. 2018 Jan;87(1):30-42.e15.

33 Mohan BP, Jayaraj M, Asokkumar R, Shakhatreh M, Pahal P, Ponnada S, et al. Lumen apposing metal stents in drainage of pancreatic walled-off necrosis, are they any better than plastic stents? A systematic review and metaanalysis of studies published since the revised Atlanta classification of pancreatic fluid collections. Endosc Ultrasound. 2019 Mar-Apr; $8(2): 82-90$

34 Trevino JM, Tamhane A, Varadarajulu S Successful stenting in ductal disruption favorably impacts treatment outcomes in patients undergoing transmural drainage of peripancreatic fluid collections. J Gastroenterol Hepatol. 2010 Mar;25(3):526-31.

35 Siddiqui AA, Dewitt JM, Strongin A, Singh H, Jordan S, Loren DE, et al. Outcomes of EUSguided drainage of debris-containing pancreatic pseudocysts by using combined endoprosthesis and a nasocystic drain. Gastrointest Endosc. 2013 Oct;78(4):589-95.

36 Siddiqui AA, Adler DG, Nieto J, Shah JN, Binmoeller KF, Kane S, et al. EUS-guided drainage of peripancreatic fluid collections and necrosis by using a novel lumen-apposing stent: a large retrospective, multicenter U.S. experience (with videos). Gastrointest Endosc. 2016 Apr;83(4):699-707. 
37 Schmidt PN, Novovic S, Roug S, Feldager E. Endoscopic, transmural drainage and necrosectomy for walled-off pancreatic and peripancreatic necrosis is associated with low mortality - a single-center experience. Scand J Gastroenterol. 2015 May;50(5):611-8.

38 Gornals JB, Consiglieri CF, Busquets J, Salord S, de-la-Hera M, Secanella L, et al. Endoscopic necrosectomy of walled-off pancreatic necrosis using a lumen-apposing metal stent and irrigation technique. Surg Endosc. 2016 Jun;30(6):2592-602.

39 Kumar N, Conwell DL, Thompson CC. Direct endoscopic necrosectomy versus step-up approach for walled-off pancreatic necrosis: comparison of clinical outcome and health care utilization. Pancreas. 2014 Nov;43(8): 1334-9.

40 Thompson CC, Kumar N, Slattery J, Clancy TE, Ryan MB, Ryou M, et al. A standardized method for endoscopic necrosectomy improves complication and mortality rates. Pancreatology. 2016 Jan-Feb;16(1):66-72.
41 Rerknimitr R. Endoscopic Transmural Necrosectomy: Timing, Indications, and Methods. Clin Endosc. 2020;53(1):49-53.

42 Varadarajulu S, Phadnis MA, Christein JD, Wilcox CM. Multiple transluminal gateway technique for EUS-guided drainage of symptomatic walled-off pancreatic necrosis. Gastrointest Endosc. 2011 Jul;74(1):74-80.

43 Bang JY, Wilcox CM, Trevino J, Ramesh J, Peter S, Hasan M, et al. Factors impacting treatment outcomes in the endoscopic management of walled-off pancreatic necrosis. J Gastroenterol Hepatol. 2013 Nov;28(11):172532.

44 Bang JY, Varadarajulu S. Management of walled-off necrosis using the multiple transluminal gateway technique with the Hot AXIOS System. Dig Endosc. 2016 Jan;28(1): 103.

45 Orr J, Yachimski P. Timing of Endoscopic Necrosectomy following Transmural Stent Placement for Pancreatic Necrosis. Curr Treat Options Gastroenterol. 2018 Dec;16(4): 622-5.

46 Yan L, Dargan A, Nieto J, Shariaha RZ, Binmoeller KF, Adler DG, et al. Direct endoscopic necrosectomy at the time of transmural stent placement results in earlier resolution of complex walled-off pancreatic necrosis: results from a large multicenter United States trial. Endosc Ultrasound. 2019 May-Jun;8(3): 172-9.
47 van der Wiel SE, May A, Poley JW, Grubben MJ, Wetzka J, Bruno MJ, et al. Preliminary report on the safety and utility of a novel automated mechanical endoscopic tissue resection tool for endoscopic necrosectomy: a case series. Endosc Int Open. 2020 Mar;8(3):E27480.

48 Amateau SK, Freeman ML. Avoidance, Recognition, and Management of Complications Associated with Lumen-Apposing Metal Stents. Gastrointest Endosc Clin N Am. 2018 Apr;28(2):219-31.

49 Boxhoorn L, Fockens P, Besselink MG, Bruno MJ, van Hooft JE, Verdonk RC, et al.; Dutch Pancreatitis Study Group. Endoscopic Management of Infected Necrotizing Pancreatitis: An Evidence-Based Approach. Curr Treat Options Gastroenterol. 2018 Sep;16(3):33344.

50 van Brunschot S, Fockens P, Bakker OJ, Besselink MG, Voermans RP, Poley JW, et al. Endoscopic transluminal necrosectomy in necrotising pancreatitis: a systematic review. Surg Endosc. 2014 May;28(5):1425-38. 